\title{
What if children with psychiatric problems disagree with their clinicians on the need for care? Factors explaining discordance and clinical directions.
}

Richard Vijverberg ( $\nabla$ r.vijverberg@ggz-delfland.nl )

GGZ Delfland https://orcid.org/0000-0002-7453-9303

Robert Ferdinand

GGZ Delfland

Aartjan Beekman

Amsterdam UMC - Locatie VUMC: Amsterdam UMC Locatie VUmc

Berno van Meijel

INHOLLAND University of Applied Sciences: Hogeschool Inholland

\section{Research article}

Keywords: Childhood, Clinicians, Disagreement, Concordance, Care Needs, Mental health care

Posted Date: October 18th, 2021

DOl: https://doi.org/10.21203/rs.3.rs-965144/v1

License: (c) (1) This work is licensed under a Creative Commons Attribution 4.0 International License. Read Full License

Version of Record: A version of this preprint was published at Child and Adolescent Psychiatry and Mental Health on February 14th, 2022. See the published version at https://doi.org/10.1186/s13034-022-00448-z. 


\section{Abstract \\ Background}

Children and adolescents in mental healthcare often perceive their care needs and necessary treatment differently from their clinicians. As such discordance between young patients and clinicians may obstruct treatment adherence and compromise treatment outcomes, it is important to understand the factors associated with it. We therefore investigated the factors associated with patient-clinician discordance with regard to care needs in various areas of functioning.

\section{Methods}

A cross-sectional study involving 244 children/adolescents aged 6-18 participating with their clinicians in treatment at a specialized mental healthcare center. As a previous study conducted by our research group had found the greatest patientclinician discordance in three CANSAS care needs - "mental health problems," "information regarding diagnosis and/or treatment," and "making and/or keeping friends" - we used univariable and multivariable statistics to investigate the factors associated with discordance regarding these three care needs.

\section{Results}

Patient-clinician discordance on the three CANSAS items was associated with child, parent, and family/social-context factors. Three variables were significant in each of the three final multivariable models: dangerous behavior towards self (child level); severity of psychiatric problems of the parent (parent level); and growing up in a single-parent household (family/social-context level).

\section{Conclusions}

To deliver treatment most effectively and to prevent drop-out, it is important during diagnostic assessment and treatment planning to address the patient's care needs at all three levels: child, parent and family/social context.

\section{Background}

If patients and clinicians in mental healthcare are to collaborate effectively, it is crucial that they agree on the care needs that need to be addressed [1-4]. By facilitating shared decision-making on treatment goals and interventions [5, 6], such agreement opens the gates to treatment adherence and effective treatment $[7,8]$.

Care needs can be defined as physical, psychological, social or environmental calls for aid, care or service in solving a problem [9]. These needs can either be 'met', which implies that a patient is receiving appropriate care, or 'unmet', which means that they are not being addressed adequately [10].

Children and adolescents who receive specialized mental healthcare often disagree with clinicians about unmet care needs [1113]. In a previous study, we used the Camberwell Assessment of Need Short Appraisal Schedule (CANSAS) to examine the extent to which children and adolescents agreed or disagreed with their clinicians on a broad range of care needs [13]; we found that they generally reported fewer unmet care needs than their clinicians. The highest discordance was found on the CANSAS items "mental health problems," "information regarding diagnosis and/or treatment," and "making and/or keeping friends."

It is likely that treatment outcomes are influenced by discordance in these clinically relevant areas [1, 3]. Thus, as the presence of mental health problems is the primary reason for providing treatment, a lack of agreement between patient and clinician on this presence would deprive treatment of its fundamental reason for being: the lack of a fundamental basis for treatment [5]. Similarly, with respect to "information regarding diagnosis and/or treatment," if a clinician believes that a patient might benefit from information about the diagnosis and options for treatment, but the patient does not see it as important, it is possible that the 
patient will have little interest in the treatment approach that the clinician proposes to deliver [14]. Discordance on the need to strengthen the patient's social network shows that a clinician has observed that a patient is not functioning well in her/his social environment, but that the patient does not consider this to be a problem $[14,15]$.

Such discordance on care needs can undermine effective collaboration, and may also reduce treatment effects [16]. It is important to clinical practice to improve our understanding of this discordance [17], and also of the factors related to it [18]. As these factors had not yet been identified, this study was intended to fill the gap by focusing explicitly on the three CANSAS items identified above.

To categorize candidate predictors of discordance, we used the Bronfenbrenner model [19], which describes factors that influence a child's functioning at three levels: that of (i) the child itself, (ii) that of his or her parents, and (iii) that of his or her family and social context. Given the lack of empirical research on discordance between children/adolescents and their clinicians regarding unmet care needs, we used studies that focused on factors associated with psychiatric problems and agreement on them.

With regard to the child level, existing studies suggest that children with more severe psychiatric problems in general, or with more severe internalizing and externalizing problems in particular, reported fewer mental health problems than their clinicians did [1,3, $20,21]$. It has also been reported that dangerous behaviors towards oneself, rule-breaking behavior, and a higher age are associated with lower patient-clinician concordance on the presence of mental health problems $[1,3,20]$.

With regard to the parent level, the literature shows that parents with higher levels of stress and more severe psychiatric problems report more mental health problems in their children than their children do [1, 21-23].

With regard to the level of the family/social context, the literature suggests that clinicians report more mental health problems than children or adolescents do in cases that involve lower family socio-economic status (SES), those that involve growing up in single-parent households, those that involve more problems with peers, and those that involve more problems at school [1,2429]. Discordance between patients and clinicians with regard to the severity of psychiatric problems was also predicted by greater child-parent discordance on the presence of mental health problems, and lower quality of the parent- child relationship $[1,3,20$, 30-32]. Given this review of literature, our a priori hypothesis was that discordance between clinicians and children/adolescents is predicted by predictors at all three levels, i.e., child, parent, and family/social context.

\section{Methods}

\section{Design}

Factors associated with patient-clinician discordance regarding unmet care needs were investigated using a cross-sectional design.

\section{Setting}

The study was conducted at the department of child and adolescent psychiatry at a large specialized mental healthcare institution in the Netherlands. This department had two general outpatient clinics and one youth-Assertive Community Treatment team (ACT). Diagnostic assessments and treatment (e.g., cognitive behavioral therapy, family support, and pharmacological treatment) were provided by three child psychiatrists, seventeen psychologists, five clinical nurse specialists, and two mental health nurses.

\section{Participants}

The target population consisted of all 6 to 18-year-olds who had been referred to the department, and their clinicians. Only one child per household was included in the study. A total of 467 patients were eligible for inclusion. The final sample consisted of 244 patients. Figure 1 shows the flow chart of the inclusion process.

\section{Ethical approval}

The study was approved by the following: the Medical Ethical Committee at VU University Medical Center Amsterdam (protocol no. 2015.245); the Scientific Committee at the Amsterdam Public Health Research Institute; and the local research committee at 
the participating mental health institution.

Separately, participating children/adolescents and clinicians received written and oral information on the research project. In accordance with prevailing Dutch legislation, the written consent of parents and/or children/adolescents was obtained on the following basis: (i) if children were younger than 12, only parents were asked for consent; (ii) if children were aged between 12 and 16, parents and children were both asked for consent; and (iii) if adolescents were 16 or older, informed consent was obtained only from the adolescents themselves.

\section{Measurement instruments}

\section{Sample descriptives}

The Demographic Information Questionnaire (DEMOG) child version was used to establish age, gender, and country of birth [33]. The Neuropsychiatric Interview for Children and Adolescent (MINI-KID) was used to establish the patients' psychiatric diagnoses [34]. If a child was aged 12 or above, the MINI-KID was administered. If a child was younger, the MINI-KID was administered in the presence of one of the parents. Parents were allowed to clarify questions for their child. For disorders that were not covered by the MINI-KID (personality disorders, autism spectrum disorders), clinical diagnoses were used.

\section{Assessment of care needs}

To assess a patient's unmet care needs, we used the Camberwell Assessment of Need Short Appraisal Schedule (CANSAS) [35], which covers 25 care need items that can be scored on a three-point scale. The response format is $0=$ no need, $1=$ met need, and $2=$ unmet need. The CANSAS was used in the form of an interview. If a child was aged 12 or older, it was administered to the child alone. If the child was younger, it was administered in the presence of one of the parents. At the start of the interview, parents were instructed not to answer for the child, but to clarify the questions in such a way that the child was able to answer the question from her or his own perspective. Simultaneously, the clinician also completed the CANSAS scoring form on the basis of all the clinical information available.

\section{Outcomes}

Three dependent variables were studied: discordance between young people and their clinicians for (i) unmet care needs regarding mental health problems, (ii) unmet care needs regarding information on diagnosis and treatment, and (iii) unmet care needs regarding making and/or keeping friends.

To determine the presence or absence of patient-clinician discordance, scores for each of the three CANSAS items were recoded into $0=$ no need $/$ met need, and $1=$ unmet need. Next, the item score of the clinician was subtracted from the patient's score: $0=$ concordance, and 1 or -1 = discordance. As a explorative investigation, the present study did not focus on the nature of discordance i.e., on whether the clinician reported more care needs than the patient, or vice versa. Hence, all negative scores $(=-1)$ were recoded into positive ones $(=1)$.

\section{Predictors}

\section{Child factors}

Candidate predictors at the child level were assessed as follows.

Severity of psychiatric problems. The Strength and Difficulty Questionnaire (SDQ, version parent) was used to assess the severity of mental health problems of the child from the parent's perspective [36]. SDQ is a questionnaire that scores 33 items on a 3-point scale, in which $0=$ not true, $1=$ somewhat true, and 2 = certainly true [37].

Severity of internalizing problems and externalizing problems. To measure the severity of internalizing problems and externalizing problems, we used two SDQ (parent version) subscales: "internalizing problems" and "externalizing problems" [38]. 
Dangerous behavior towards self. To measure whether a patient currently showed dangerous behavior towards themselves, we used the MINI-KID domain "suicidal risk" (no = 0, or yes $=1$ ) [34].

Rule-breaking behavior. The MINI-KID domains "conduct disorder" and "oppositional deviant disorder" were used to estimate rulebreaking behavior (diagnosis absent $=0$, diagnosis present $=1$ ) [34].

Age. The age of the child/adolescent was measured using the DEMOG [33].

\section{Parent factors}

Candidate predictors at the parent level were assessed as follows:

Degree of parental stress. The Parental Stress Scale was used to measure the degree of parental stress by asking primary caregivers to indicate their degree of parenting stress on a scale ranging from 1 to 10 .

Severity of psychiatric problems. The Health of the Nation Outcomes Scale (HoNOS) sum score was used to measure the severity of the parent's psychiatric problems [39]. The HoNOS consists of 12 items to be scored on a 5-point-Likert scale, ranging from 0 (no problems) to 4 (severe problems).

\section{Family/social-context factors}

Candidate predictors at the family/social-context level were assessed as follows:

Family SES. Family SES, expressed as the highest educational achieved by the parents, was measured using the DEMOG-Adult.

Growing up in a single-parent household. The DEMOG-Adult was also used to determine whether a child was growing up in singleparent or two-parent household [33].

Severity of problems with peers. The Kidscreen-27 (parent version) "friends" subscale was used to assess problems with peers as perceived by the parents. This subscale comprises spending time with friends, fun with friends, support from friends, the extent to which a child could trust his/her friends. Originally, higher item scores on Kidscreen-27 reflect better functioning, and range from 0 (= never) to 4 (= always). As we wanted to use an indicator that reflected greater severities of problems with friends as a candidate predictor, we recoded all item scores $(0=4,1=3,2=2,3=1,4=0)$ before calculating a sum score.

Severity of problems related to school. To measure parents' view of the severity of their child's school problems, we used the parent version of the Kidscreen-27 subscale "school and learning," which taps "had a good time at school," "it went well at school," "was able to pay attention in class," and "quality of contact with teachers." A sum score was for this scale was calculated similarly as for the scale regarding "problems with peers."

Severity of child-parent discordance on mental health problems. The child and parent version of the Strength and Difficulty Questionnaire (SDQ) were used to assess the severity of child-parent discordance regarding the presence of mental health problems [36]. Higher item scores of the SQD reflect more difficulties, and range from 0 (= not true) to 2 (= certainly true). The discordance was calculated by first subtracting the parent score from the child score for each item separately, which yielded discrepancy scores for each item. We then recoded all negative scores as positive scores. Finally, we summed all discrepancy scores [37]. A higher sum score thus indicates greater discordance.

Quality of the parent-child relationship. The "parent version" of the Kidscreen-27 "family" subscale was used to assess the quality of the parent-child relationship. The "family" subscale covers 3 items: "support from parents," "treated fairly by parents," and "communication with parents." Items are scored on a 5-point-Likert scale ranging from 0 (= never) to 4 (= always). To calculate the quality of the parent-child relationship, the scores of all 3 items were summed [40].

\section{Data analysis}

To analyze background characteristics, we first calculated descriptive statistics of the sample. Next, we conducted a set of univariable binary logistic regression analyses by using (i) concordance/discordance between young patients and their clinicians 
for each of the three outcomes variables ("mental health problems," "information regarding diagnosis and/or treatment," and "making and/or keeping friends"; and (ii) candidate predictors at all three levels of the Bronfenbrenner model (child / parent / family, social context). A separate regression analysis was performed for each candidate predictor $(P<0.10)$ [41], and yielded information on predictors at the child, parent, and family/social-context levels that predicted discordance between patient and clinician regarding the three outcomes. Our a priori hypothesis was that discordance between clinicians and children/adolescents would be predicted by predictors at child level, parent level, and family/social-context level. Since predictors at different levels may correlate despite being significant in univariable analyses, we then conducted stepwise multivariable logistic regression analyses to identify predictors at each level that were independent of other predictors, either at the same level, or at other levels. Therefore, stepwise multivariable logistic regression analyses were conducted for each of the three outcomes variables. As a first step, all child-level predictors that were significant in the set of univariable analyses were entered as possible predictors. Next, variables at parent level were entered, following by variables at family/social-context level. This step-by-step approach did not violate the statistical rule of 10 events per 1 variable $[42,43]$. To test the assumptions of linearity and homoscedasticity, we generated a scatter plot of the standardized residuals [44], and tested assumptions of the logistic regression analyses for indications of multicollinearity by investigating the variance inflation factor (VIF) [41]. To measure the predictive value of models, we used the Hosmer and Lemeshow goodness-of-fit-test. Nagelkerke $\mathrm{R}^{2}$ was used to obtain an indication of the strength of the relationship between the predictor and the outcome variable [41]. All statistical analyses were performed using SPSS version 24.

\section{Results}

\section{Sample characteristics}

Table 1 shows the characteristics of the patients in the study sample $(n=244)$. Mean age was 12.4 years (sd $=3.3)$. A majority of the patients were boys (57.2\%). Most patients were growing-up in a two-parent household (66.3\%). The most frequent diagnoses were attention deficit hyperactivity disorder (43.4\%), anxiety disorder (36.5\%), autism spectrum disorder $(25.4 \%)$, mood disorder (21.7\%), and behavior disorder (20.9\%).

\section{Mental health problems}

The univariable analyses presented in Table 2 show that discordance between patients and clinicians on unmet mental healthcare needs was associated with all but three candidate predictors: (i) severity of the child's externalizing psychiatric problems, (ii) family SES, and (iii) quality of the parent-child relationship.

Table 3 shows that the final step of the multivariable analysis produced two significant predictors at child level: dangerous behavior towards self, and rule-breaking behavior. Significant parent-level predictors were degree of parental stress, and severity of the parent's psychiatric problems. Predictors at family/social-context level were growing up in a single-parent household, and degree of discordance between parent and child on the severity of the child's mental health problems. The final model showed a good fit of the data (Hosmer-Lemeshow, $\mathrm{P}=0.645$ ), and a relatively strong relationship between predictor variables and outcome (Nagelkerke $\left.\mathrm{R}^{2}=0.575\right)$.

\section{Information on diagnosis and treatment}

With regard to the univariable analysis, Table 2 shows that discordance regarding the need for information on diagnosis and treatment was significantly associated with all predictor variables, except for family SES, higher age of the child, and quality of the parent-child relationship.

With regard to the final step of the multivariable analyses, Table 4 shows that, at the child level, discordance on the care need "information on diagnosis and treatment" was predicted by dangerous behavior towards self. At the parent level, discordance was predicted by the presence of the parent's psychiatric problems. At family/social-context level there were two significant predictors: growing up in a single-parent household, and discordance between parent and child on the presence of mental health problems in the child. The final model fitted the data well (Hosmer-Lemeshow, $\mathrm{P}=0.571$ ), and showed a relatively strong relationship between predictor variables and outcome (Nagelkerke $\left.\mathrm{R}^{2}=0.451\right)$. 


\section{Making and keeping friends}

Table 2 shows that discordance on the care need "making and keeping friends" was significantly associated with all variables in the univariable analyses, except for family SES, and quality of the parent-child relationship.

With regard to the final step of the multivariable analyses, Table 5 showed two child-level predictors: severity of the child's psychiatric problems, and dangerous behavior towards self. Parent-level predictors were degree of parental stress, and severity of the parent's psychiatric problems. At the family/social-context level, discordance was predicted by growing up in a single-parent household. The model showed a good fit of the data (Hosmer-Lemeshow, $\mathrm{P}=0.403$ ), and a relatively strong relationship between the predictor variables and the outcome (Nagelkerke $\left.\mathrm{R}^{2}=0.542\right)$.

\section{All three care needs}

Patient-clinician discordance on all three predefined CANSAS items was associated with child, parent, and family/social-context factors. The three final multivariable models found three common significant predictors: dangerous behavior towards self (child level); severity of the parent's psychiatric problems (parent level); and growing up in a single-parent household (family/socialcontext level).

\section{Discussion}

This study examined associations between patient, parent, and family/social-context variables on the one hand, and patientclinician discordance on regarding unmet need for care on the other. We investigated discordance for the following unmet needs for care: (i) mental health problems, (ii) information regarding diagnosis and/or treatment, and (iii) making and/or keeping friends. In the present sample, discordance on these three unmet care needs indicated mainly that clinicians deemed care to be necessary, whereas patients did not. As we had hypothesized, discordance between clinicians and children/adolescents was predicted by predictors at child, parent, and family/social-context levels.

Most of the variables that were analyzed univariably were associated with discordance between patient and clinician on all three care needs (see Table 2). As stated above, we conducted multivariable stepwise logistic regression analyses to identify which predictors predicted this discordance independently of other predictors, and to investigate whether variables at all three levels were needed to obtain the strongest predictive model. As this resulted in three final models (for all three outcomes) that encompassed predictors from all levels, discordance between patients and clinicians was truly predicted by information on children, parents, and the family/social context.

Below, we summarize which variables predicted discordance with respect to the three care needs in the multivariable models (see Tables 3, 4 and 5). As these analyses showed which predictors were the most useful in predicting discordance, the final statistical models tended to present a prototypical picture of patients who disagreed with their clinician on their need for care, and of their parents and family/social context.

\section{Disagreement on all three outcomes predicted by child level variables (final set of analyses)}

Many patients who disagree with their clinicians on the three care needs we examined often show dangerous behavior towards themselves (e.g., suicide attempt, self-harming behavior). It seems that dangerous behavior is less a reason to seek help than a more modest demand for mental health support. This can be explained in various ways. Suicidal thoughts or self-harm may indicate that a patient no longer sees a way out, and thus tends to think that care will not be helpful [45]. Similarly, patients who harm themselves may consider self-harm to be a better way of coping with negative emotions than treatment is [45]. In many cases they may have lost confidence in the ability of other people to help relieve their suffering. Self-harm may lead to the immediate alleviation of negative thoughts or feelings (such as tension, anxiety or anger), or may increase social support or attention [46]. It is possible that such reinforcement affects a patient's perceived need for care. In contrast, clinicians of patients who harm themselves may see opportunities for improvement, and may therefore indicate that care is needed.

\section{Disagreement on all three outcomes predicted by parent-level variables (final set of analyses)}


Children and adolescents who tended to disagree with clinicians about all three care needs had parents with psychiatric problems. Due these problems, clinicians may believe that these young people have more care needs, reasoning that the children of such parents are at greater risk, and thus require more attention. It is also the case that parents with psychiatric problems are more likely to report severer problems in their children, whatever the actual severity $[47,48]$. This may lead clinicians to judge that care is needed, while the young people rate themselves as being less in need of help $[1,27]$. Another possible explanation is that young people who grow up with parents with mental health problems have become accustomed to problems, and believe that they cannot be resolved $[49,50]$.

\section{Disagreement on all three outcomes predicted by family/social-context level variables (final set of analyses)}

We found that many young people who disagreed with their clinicians on all three of the care needs studied had grown up in a single-parent household. It is conceivable that clinicians rate care needs more highly if they feel that a child is less protected, in view of the fact that there is one parent rather than two. Alternatively, parents who run a single-parent household may report relatively high problem levels, and stress the need for care, as they are caring for their children on their own. This may cause clinicians, too, to give higher ratings to need for care.

\section{Other significant findings}

We found that the degree of a child's rule-breaking behavior (as assessed after a standardized interview with the child), predicted patient-clinician discordance on unmet need for care for mental health problems.

It is possible that young patients who break rules are less aware of their problems, or do not see the need for change [51]. Any negative experiences with adults [52] - who make and enforce rules - may also negatively affect their motivation for collaborating with treatment intended to resolve problems. [53].

For two of the three unmet care needs we investigated - unmet care needs regarding mental health problems, and information regarding diagnosis and/or treatment - we found that the degree of discordance between parent and child also predicted discordance between patient and clinician. As proposed previously $[13,26,48]$, this may mean that clinicians agree more with parents than with their children/adolescents, thus possibly indicating that clinicians take parents more seriously than they take young people.

Alternatively, children/adolescents who disagree with their parents may also tend to disagree with clinicians [47, 48]. Previous research showed that, irrespective of the actual severity, more parents with high stress levels tend to report a greater problem severity in their children $[47,48]$. In theory, this might cause clinicians to give a higher rating to needs for care, and therefore to inflate patient-clinician disagreement. [1,27]. However, we found that one specific association at least was independent of the degree of parental stress: that between child-parent disagreement and child/clinician disagreement.

\section{Clinical implications}

In the context of personalized care, care needs should be assessed from the start of the treatment trajectory [54]. They can be addressed properly only if they are examined systematically from the perspectives of the key people involved in treatment $[13,54]$. Our findings show that special attention should be paid to the particular perspective on care needs that applies to patients who harm themselves, exhibit suicidal behaviors, break rules, have parents with psychiatric problems, disagree with their parents on the presence of mental health problems, and grow up in a single-parent households. If patient-clinician perceptions differ, clinicians are advised to resolve the most important differences before treatment is delivered [55]. Given that positive treatment outcomes are associated with a good therapeutic relationship [4], it is important to debate differences in a way that enables the "bond" in the patient-clinician dyad to remain intact $[16,56]$. However, due to the importance of factors at parent and family/context levels - such as parental psychiatric problems and growing up in a single-parent household - it is probably not effective to solve discordances solely through this dyad. It is therefore important to discuss patients' needs for care in the triad of patient, parent, and clinician, paying specific attention to the predictive factors outlined above that significantly contribute to discordance. 
Fruitful therapeutic relationships within this triad will contribute to positive treatment outcomes and the prevention of drop-out from treatment. Establishing such relationships must start with a shared view of the care that is needed. It means that patients' perspectives on care their needs should be taken seriously. It also means seeking shared goals and making decisions on interventions collaboratively - together with patients, not for them [53].

These guidelines for a care-needs-based approach provide a flexible framework that gives guidance to clinicians, while leaving them scope for appropriate action on individual and situational peculiarities. To encourage and facilitate discussion of different viewpoints on care needs, various patient-centered communication techniques can be used, including (i) motivational interviewing techniques that are characterized by bond-building, empathy, interpersonal sensitivity, and the provision of information [54]; and (ii) shared decision, which may help to establish a process for collaboratively making decisions about the care needs that will be targeted during treatment [55].

\section{Strengths/limitations}

This study has several strengths. To our knowledge, it is the first to provide insight into factors that are associated with discordance between patients and clinicians on unmet care needs $[26,55,56]$. Due to our use of more than one outcome variable for child/adolescent-clinician discordance, we were able to identify factors that predict discordance on unmet care needs.

Knowledge obtained may contribute to a more personalized form of care that enables patients to better identify with the treatment provided [10]. This knowledge may help patients to feel more engaged in treatment, and to prevent non-adherence and drop-out [57]. Finally, our use of hierarchical analyses made it possible to investigate relevant predictors at child, parent, and family/socialcontext levels.

A limitation is that our data were collected at a single mental health organization. For this reason, our results can generalized only with reservations [58].

\section{Conclusion}

We found that discordance between young people and clinicians on unmet care needs were associated with factors at child, parent, and family/social-context levels. On this basis, we conclude that it is important to the effective delivery of treatment and the prevention of drop-out to address all three levels during diagnostic assessment and psychiatric treatment.

\section{Abbreviations}

ASD: Autism spectrum disorder; ADHD: Attention deficit hyperactivity disorder; CANSAS: Camberwell Assessment of Need Short Appraisal Schedule; Cl: Confidence interval; GAF-score: Global Assessment of Functioning score; HoNOS: health of the nation outcomes scale; MINI-KID: MINI International Neuropsychiatric Interview for Children and Adolescents; N: number of patients; OR: odds ratio; SD: Standard Deviation; SDQ: strength and difficulty questionnaire; SES: social economic status; SPSS: Statistical Package for the Social Sciences.

\section{Declarations}

\section{Ethics approval}

The study was approved by the Medical Ethics Committee on Research Involving Human Subjects at VU University Medical Centre, Amsterdam (protocol no. 2015.245).

\section{Consent to participate}

Participants received written and oral information on the research project; children and parents received this separately. Prior to participation, written consent was obtained from the parents and/or children according to three age categories: Category 1 : Parents were asked for consent for children aged $<12$. Category 2: If children were aged between 12 and $<16$, parents and 
children alike were asked for consent. Category 3: Informed consent was obtained from children (not parents) only if they were aged $\geq 16$.

\section{Consent to publish}

Not applicable.

\section{Availability of data and materials}

The datasets used and/or analyzed during the current study are available from the corresponding author on reasonable request.

\section{Competing interests}

The authors declare that they have no competing interests.

\section{Funding}

This research was funded by GGZ Delfland Psychiatric Institute, which played no role in the design of the study, in the collection, analysis or interpretation of the data; or in writing the manuscript.

\section{Authors' contributions}

$\mathrm{RV}, \mathrm{RF}, \mathrm{AB}$ and $\mathrm{BM}$ designed this study. RV and RF performed the analysis and interpreted the data. RV and RF wrote the manuscript. BM and $A B$ critically revised it. All authors read and approved the final manuscript.

\section{Acknowledgements}

The authors gratefully acknowledge the families and mental healthcare providers who participated. We also acknowledge research assistant Amanda Noorman, who helped to conduct the study. We would also like to thank Daphne van de Draai for her assistance with building the SPSS files.

\section{Authors' information}

${ }^{1}$ GGZ Delfland, Department of Child and Adolescent Psychiatry, Delft, the Netherlands

2 Inholland University of Applied Sciences, Department of Health, Sports \& Social Work, Amsterdam, the Netherlands

${ }^{3}$ Amsterdam UMC (VUmc), Department of Psychiatry, Amsterdam Public Health Research Institute, Amsterdam, the Netherlands

${ }^{4}$ Parnassia Psychiatric Institute, The Hague, the Netherlands.

\section{References}

1. Hawley K, Weisz J. Child, parent, and therapist (dis)agreement on target problems in outpatient therapy: the therapist's dilemma and its implications. J Consult Clin Psychol. 2003;71(1):62-70.

2. Garcia J, Weisz J. When youth mental health care stops: therapeutic relationship and other reasons for ending youth outpatient treatment. J Consult Clin Psychol. 2002;70(2):439-43.

3. Hawley K, Garland A. Working alliance in adolescent outpatient therapy: youth, parent and therapist reports and associations with therapy outcomes. Child youth care forum. 2008;37(2):59-74.

4. Fjermestad K, Lerner M, McLeod B, Wergeland G, Heiervang E, Silverman W, et al. Therapist-youth agreement on alliance change predicts long-term outcome in CBT for anxiety disorders. J Child Psychol Psychiatry. 2016;57(5):625-32.

5. Tryon G, Winograd G. Goal consensus and collaboration. Psychotherapy (Chic). 2011;48(1):50-7.

6. Fukuni S, Salyers M, Matthias M, Collins L, Thompson J, Coffman M, et al. Predictors of shared decision making and level of agreement between consumers and providers in psychiatric care. Community Ment Health J. 2014;50(4):375-82. 
7. Weisz J, Chorpita B, Frye A, Ng M, Lay N, Bearman S, et al. Youth top problems: using idiographic, consumer-guided assessment to identify treatment needs and to track change during psychotherapy. J Consult Clin Psychol. 2011;79(3):36980 .

8. Ford T, Macdiarmid F, Russell D, Racey D, Goodman R. The predictors of persistent DSM-IV disorders in 3-years follow-ups of the British child and adolescent mental health surveys 1999 and 2004. Psychol Med. 2017;47(6):1126-37.

9. Houtjes W. Needs of elderly people with late-life depression; challenges for care improvement. Amsterdam: Vrije Universiteit; 2015.

10. Phelan M, Slade M, Thornicroft G, Dunn G, Holloway, et al. The Camberwell Assessment of Need: the validity and reliability of an instrument to assess the needs of people with severe mental illness. Br J Psychiatry. 1995;167(5):589-95.

11. Corkum P, Bessey M, McGonnell M, Dorbeck A. Barriers to evidence-based treatment for children with attentiondeficit/hyperactivity disorder. Atten Defic Hyperact Disord. 2015;7(1):49-74.

12. De Los Reyes A, Ohannessian C. Introduction to the special issue: discrepancies in adolescent-parent perceptions of the family and adolescent adjustment. J Youth Adolescence. 2016;45(10):1957-72.

13. Vijverberg R, Ferdinand R, Beekman A, van Meijel B. Agreement between patients and mental healthcare providers on unmet care needs in child and adolescent psychiatry. Soc Psychiatry Psychiatr Epidemio. 2020. doi:10.1007/s00127-020-01969-8.

14. Clever S, Ford D, Rubenstein L, Rost K, Meredith L, Sherbourne C, et al. Primary care patients' involvement in decision-making is associated with improvement in depression. Med Care. 2006;44(5):398-405.

15. Powers A, Ressler K, Bradley R. The protective role of friendship on the effects of childhood abuse and depression. Depress Anxiety. 2009;26(1):46-53.

16. DiGuiseppe R, Linscott J, Jilton R. Developing the therapeutic alliance in child-adolescent psychotherapy. Appl Prev Psychol. 1996;5(2):85-100.

17. Yeh M, McCabe K, Ahmed S, Trang D, Ganger W. Sociocultural factors and parent-therapist agreement on explanatory etiologies for youth mental health problems. Adm Policy Ment Health. 2016;43(5):693-702.

18. Karver M, Monahan M, De Nadai A, Shirk S. Meta-analysis of the prospective relation between alliance and outcome in child and adolescent psychotherapy. Psychotherapy (Chic). 2018;55(4):341-55.

19. Bronfenbrenner U, Morris P. The bioecological model of human development. In: Lerner R, editor. Handbook of Child Psychology. 6th ed. New York: John Wiley \& Sons Inc; 2007.

20. Dolle K, Schulte-Körne G, von Hofacker N, Izat Y, Allgaier A. Agreement of clinical diagnosis, structured interviews, and selfreport questionnaires for depression in children and adolescent. Z Kinder Jugendpsychiatr Psychother. 2012;40(6):405-14.

21. Hoffman L, Chu B. Target problems (mis) matching: predictors and consequences of parent-youth agreement in a sample of anxious youth. J Anxiety Disord. 2015;31:11-9.

22. Penney S, Skilling T. Moderators of informant agreement in the assessment of adolescent psychopathology: extension to a forensic sample. Psychol Assess. 2012;24(2):386-401.

23. Grills A, Ollendick T. Issues in parent-child agreement: the case of structured diagnostic interviews. Clin Child Fam Psychol Rev. 2002;5(1):57-83.

24. Yin H, Johnson M, Mendelsohn A, Abrams M, Sanders L, Dreyer B. The health literacy of parents in the United States: a nationally representative study. Pediatrics. 2009;124(Suppl 3):289-98.

25. Zane N, Sue S, Chang J, Huang L, Huang J, Lowe S, et al. Beyond ethnic match: effects of client-therapist cognitive match in problem perception, coping orientation, and therapist goals on treatment outcomes. J Community Psychol. 2005;33(5):56985.

26. De Los Reyes A, Augenstein T, Wang M, Thomas S, Drabick D, Burgers D, et al. The validity of the multi-informant approach to assessing child and adolescent mental health. Psychol Bull. 2015;141(4):858-900.

27. Youngstrom E, Kogos Youngstrom J, Freeman A, De Los Reyes A, Feeny N, Findling R. Informants are not equal: predictors and correlates of clinician judgments about caregiver and youth credibility. J Child Adolesc Psychopharmacol.

2011;21(5):407-15. 
28. Jensen P, Xenakis S, Davis H, Degroot J. Child psychopathology rating scales and interrater agreement: II Child and family characteristics. J Am Acad Child Adolesc Psychiatry. 1988;27(4):451-61.

29. Fisher J, Lichvar E, Hogue A, Dauber S. Perceived need for treatment and engagement in mental health services among community-referred racial/ethnic minority adolescents. Adm Policy Ment Health. 2018;45(5):751-64.

30. Ehrlich K, Cassidy J, Dykas M. Reporter discrepancies among parents, adolescents, and peers: adolescent attachment and informant depressive symptoms as explanatory factors. Child Develop. 2011;82(3):999-1012.

31. Salbach-Andrae H, Lenz K, Lehmkuhl U. Patterns of agreement among parent, teacher and youth ratings in a referred sample. Eur Psychiatry. 2009;24(5):345-51.

32. Salbach-Andrae H, Klinkowski N, Lenz K, Lehmkuhl U. Agreement between youth-reported and parent reported psychopathology in a referred sample. Eur Child Adolesc Psychiatry. 2009;18(3):136-43.

33. Reflectum. Bibliotheek vragenlijsten NVPP/LVE. Deventer: Reflectum; 2013.

34. Sheehan D, Sheehan K, Shytle R, Janavs J, Bannon Y, Rogers J, et al. Reliability and validity of the mini international neuropsychiatric interview for children and adolescents. J Clin Psychiatry. 2010;71(3):313-26.

35. Phelan M, Slade M, Thornicroft G, Dunn G, Holloway F, Wykes T. The Camberwell Assessment of Need: the validity and reliability of an instrument to assess the needs of people with severe mental illness. Br J Psychiatry. 1995;167(5):589-95.

36. van Widenfelt B, Goedhart A, Treffers P, Goodman R. Dutch version of the Strengths and Difficulties Questionnaire (SDQ). Eur Child Adolesc Psychiatry. 2003;12(6):281-9.

37. van der Meer M, Dixon A, Rose D. Parent and child agreement on reports of problem behavior obtained from a screening questionnaire, the SDQ. Eur Child Adolesc Psychiatry. 2008;17(8):491-7.

38. Tiffin P, Rolling K. Structure of the Health of the Nation Outcome Scales for Children and Adolescents: an ordinal factor analysis of clinician ratings of a sample of young people referred to community mental health services. Psychiatry Res. 2012;197(1-2):154-62.

39. Kisely S, Campbell L, Cartwright J, Cox M, Campbell J. Do the Health of the nation outcome scales measure outcome? Can J Psychiatry. 2010;55(7):431-9.

40. Ravens-Sieberer U, Herdman M, Devine J, Otto C, Bullinger M, Rose M, et al. The European KIDSCREEN approach to measure quality of life measure for and wellbeing of children: development, current application, and future advances. Qual Life Res. 2014;23(3):791-803.

41. Pallant J. SPSS survival manual. Berkshire: Open university press; 2013.

42. van Belle G. Statistical rules of tumb. Washington: John Wiley And Sons Ltd; 2008.

43. Vittinghoff E, McCulloch C. Relaxing the rule of ten events per variable in logistic and Cox regression. Am J Epidemiol. 2006;165(6):710-8.

44. Tabachnick B, Fidell L. Using multivariate statistics. Harlow: Pearson education limited; 2014.

45. Nock M, Prinstein M. A functional approach to the assessment of self-mutilative behavior. J Consult Clin Psychol. 2004;72(5):885-90.

46. Nock M, Prinstein M. Contextual features and behavioral functions of self-mutilation among adolescents. J Abnorm Psychol. 2005;114(1):140-6.

47. Bajeux E, Klemanski D, Husky M, Leray E, Chan Chee C, Shojaei T, et al. Factors associated with parent-child discrepancies in reports of mental health disorders in young children. Child Psychiatry Hum Dev. 2018;49(6):1003-10.

48. Kassam-Adams N, García-España J, Miller V, Winston F. Parent-child agreement regarding children's acute stress: the role of parent acute stress reactions. J Am Acad Child Adolesc Psychiatry. 2006;45(12):1485-93.

49. Balcher E, Frühmann A, Strunk G, Bachler H, Aas B, Strunk G, et al. Differential effects of the working alliance in family homebased treatment of multi-problem families. J Fam Ther. 2016;38(1):120-48.

50. Vaessen G. Multi-probleemgezinnen in de jeugdzorg. Antwerpen-Apeldoorn: Garant; 2009.

51. Erickson S, Gerstle M, Feldstein S. Brief interventions and motivational interviewing with children, adolescents, and their parents in pediatric health care settings: a review. Arch Pediatr Adolesc Med. 2005;159(12):1173-80. 
52. Vijverberg R, Ferdinand R, van Meijel B, Beekman A. Unmet care needs of children with ADHD. PLoS One. 2020;15:e0228049.

53. Westermann G, Maurer J. Shared decision-making in mental health care: a role model from youth mental health care. Tijdschr Psychiatr. 2015;57(5):352-60.

54. Huber L, Plötner M, Schmitz J. Social competence and psychopathology in early childhood: a systematic review. Eur Child Adolesc Psychiatry. 2019;28(4):443-59.

55. Lasalvia A, Bonetto C, Tansella M, Stefani B. Does staff-patient agreement on needs for care predict a better mental health outcome? A 4-year follow-up in a community service. Psychol Med. 2007;38(1):123-33.

56. Eklund H, Findon J, Cadman T, Hayward H, Murphy D, Asherson P, et al. Needs of adolescents and young adults with neurodevelopmental disorders: comparisons of young people and parent perspectives. J Autism Dev Disord. 2018;48(1):8391.

57. de Haan A, Boon A, de Jong J, Hoeve M, Vermeiren R. A meta-analytic review on treatment dropout in child and adolescent outpatient mental health care. Clin Psychol Rev. 2013;33(5):698-711.

58. Polit D, Beck C. Nursing Research: Generating and Assessing Evidence for Nursing Practice. London: Lippincott, Williams and Wilkins; 2017.

\section{Tables}




\begin{tabular}{|c|c|c|}
\hline & Patient & \\
\hline & $N=244$ & \\
\hline \multirow[t]{6}{*}{ Age (sd) } & Total mean & $12.4(3.3)$ \\
\hline & range & $6-18$ \\
\hline & Boys mean & $11.8(3.2)$ \\
\hline & range & $6-17$ \\
\hline & Girls mean & $13.1(3.2)$ \\
\hline & range & $6-18$ \\
\hline \multirow[t]{2}{*}{ Gender } & Boys & $57.2 \%$ \\
\hline & Girls & $42.8 \%$ \\
\hline \multirow[t]{2}{*}{ Country of birth } & The Netherlands & $95.9 \%$ \\
\hline & Other & $4.1 \%$ \\
\hline \multirow[t]{10}{*}{ Clinical diagnoses } & $A D H D$ & $43.4 \%$ \\
\hline & Anxiety & $36.5 \%$ \\
\hline & ASD & $25.4 \%$ \\
\hline & Mood & $21.7 \%$ \\
\hline & Behavior & $20.9 \%$ \\
\hline & Somatoform & $6,6 \%$ \\
\hline & Personality & $2.9 \%$ \\
\hline & Psychotic & $2.0 \%$ \\
\hline & Drugs/alcohol & $1.6 \%$ \\
\hline & Other & $2.0 \%$ \\
\hline \multirow[t]{2}{*}{ GAF-score (sd) } & Mean & $50.5(8.2)$ \\
\hline & Range & $15-75$ \\
\hline \multirow[t]{2}{*}{ Living situation } & Two parent & $66.3 \%$ \\
\hline & Single parent & $33.7 \%$ \\
\hline
\end{tabular}

$\mathrm{N}$ : number of included patients; sd: standard deviation; ADHD: attention deficit hyperactivity disorder; ASD: autism spectrum disorder; GAF: general assessment of functioning. 
Table 2. Factors associated with patient-clinician discordance on unmet care needs with regard to:

$$
\begin{array}{ll}
\text { Mental health problems } & \begin{array}{l}
\text { Information regarding } \\
\text { diagnosis and/or treatment }
\end{array} \quad \text { Making and keeping friends }
\end{array}
$$

$\begin{array}{lllllllllllll}\mathrm{N} & \mathrm{OR} & \begin{array}{l}95 \% \\ \mathrm{Cl}\end{array} & P & \mathrm{~N} & \text { OR } & \begin{array}{l}95 \% \\ \mathrm{Cl}\end{array} & P & \mathrm{~N} & \text { OR } & \begin{array}{l}95 \% \\ \mathrm{Cl}\end{array} & P\end{array}$

\section{Child level}

\begin{tabular}{|c|c|c|c|c|c|c|c|c|c|c|c|c|}
\hline $\begin{array}{l}\text { Severity of } \\
\text { psychiatric problems }\end{array}$ & 244 & 1.077 & $\begin{array}{l}1.034- \\
1.123\end{array}$ & $<.001$ & 244 & 1.086 & $\begin{array}{l}1.042- \\
1.131\end{array}$ & $<.001$ & 244 & 1.113 & $\begin{array}{l}1.065- \\
1.164\end{array}$ & $<.001$ \\
\hline $\begin{array}{l}\text { Severity of } \\
\text { internalizing } \\
\text { problems }\end{array}$ & 244 & 1.129 & $\begin{array}{l}1.033- \\
1.235\end{array}$ & 0.008 & 244 & 1.070 & $\begin{array}{l}0.987- \\
1.159\end{array}$ & 0.099 & 244 & 1.152 & $\begin{array}{l}1.051- \\
1.263\end{array}$ & 0.003 \\
\hline $\begin{array}{l}\text { Severity of } \\
\text { externalizing } \\
\text { problems }\end{array}$ & 244 & 1.094 & $\begin{array}{l}0.975- \\
1.229\end{array}$ & 0.126 & 244 & 1.182 & $\begin{array}{l}1.046- \\
1.337\end{array}$ & 0.007 & 244 & 1.152 & $\begin{array}{l}1.022- \\
1.300\end{array}$ & 0.021 \\
\hline \multicolumn{13}{|l|}{ Dangerous behavior } \\
\hline $\begin{array}{l}\text { Dangerous behavior } \\
\text { towards self } \\
\text { (yes/no) }\end{array}$ & 244 & 5.268 & $\begin{array}{l}2.980- \\
9.312\end{array}$ & $<.001$ & 244 & 4.182 & $\begin{array}{l}2.404- \\
7.277\end{array}$ & $<.001$ & 244 & 5.582 & $\begin{array}{l}3.156- \\
9.871\end{array}$ & $<.001$ \\
\hline $\begin{array}{l}\text { Rule-breaking } \\
\text { behavior (yes/no) }\end{array}$ & 244 & 3.647 & $\begin{array}{l}2.024- \\
6.571\end{array}$ & $<.001$ & 244 & 3.072 & $\begin{array}{l}1.760- \\
5.364\end{array}$ & $<.001$ & 244 & 3.632 & $\begin{array}{l}2.031- \\
6.494\end{array}$ & $<.001$ \\
\hline Age & 243 & 1.823 & $\begin{array}{l}1.033- \\
3.219\end{array}$ & 0.038 & 243 & 1.332 & $\begin{array}{l}0.776- \\
2.288\end{array}$ & 0.299 & 243 & 1.978 & $\begin{array}{l}1.122- \\
3.486\end{array}$ & 0.018 \\
\hline $4-11$ & 90 & & & & 90 & & & & 90 & & & \\
\hline $12-18$ & 153 & & & & 153 & & & & 153 & & & \\
\hline
\end{tabular}

\section{Parent level}

\begin{tabular}{|c|c|c|c|c|c|c|c|c|c|c|c|c|}
\hline $\begin{array}{l}\text { Degree of parental } \\
\text { stress }\end{array}$ & 244 & 1.525 & $\begin{array}{l}1.316- \\
1.768\end{array}$ & $<.001$ & 244 & 1.265 & $\begin{array}{l}1.121- \\
1.427\end{array}$ & $<.001$ & 244 & 1.407 & $\begin{array}{l}1.229- \\
1.609\end{array}$ & $<.001$ \\
\hline $\begin{array}{l}\text { Severity of parent's } \\
\text { psychiatric problems }\end{array}$ & 244 & 1.232 & $\begin{array}{l}1.163- \\
1.305\end{array}$ & $<.001$ & 244 & 1.163 & $\begin{array}{l}1.107- \\
1.221\end{array}$ & $<.001$ & 244 & 1.236 & $\begin{array}{l}1.166- \\
1.310\end{array}$ & $<.001$ \\
\hline
\end{tabular}

\section{Family/social- context level}

\begin{tabular}{|c|c|c|c|c|c|c|c|c|c|c|c|c|}
\hline & 244 & & & & 244 & & & & 244 & & & \\
\hline status & 86 & & & 0.644 & 86 & & & 0.131 & 86 & & & 0.433 \\
\hline Basic & 112 & 0.835 & $0.467-$ & 0.544 & 112 & 0.553 & $0.310-$ & 0.044 & 112 & 0.892 & $0.502-$ & 0.698 \\
\hline Intermediate & 46 & 0.703 & & 0.365 & 46 & 0.739 & & 0.416 & 46 & 0.602 & & 0.199 \\
\hline High & & & 1.508 & & & & 1.531 & & & & $1.306^{-}$ & \\
\hline $\begin{array}{l}\text { Child growing up in a } \\
\text { single-parent } \\
\text { household }\end{array}$ & 244 & 4.588 & $\begin{array}{l}2.618- \\
8.042\end{array}$ & $<.001$ & 244 & 3.110 & $\begin{array}{l}1.813- \\
5.335\end{array}$ & $<.001$ & 244 & 3.510 & $\begin{array}{l}2.030- \\
6.072\end{array}$ & $<.001$ \\
\hline $\begin{array}{l}\text { Quality of the parent- } \\
\text { child relationship }\end{array}$ & 238 & 0.997 & $\begin{array}{l}0.935- \\
1.063\end{array}$ & 0.920 & 238 & 0.996 & $\begin{array}{l}0.935- \\
1.061\end{array}$ & 0.904 & 238 & 0.975 & $\begin{array}{l}0.915- \\
1.039\end{array}$ & 0.435 \\
\hline $\begin{array}{l}\text { Degree of } \\
\text { discordance between } \\
\text { parent and child on } \\
\text { the child's mental } \\
\text { health problems }\end{array}$ & 190 & 1.168 & $\begin{array}{l}1.096- \\
1.245\end{array}$ & $<.001$ & 190 & 1.168 & $\begin{array}{l}1.096- \\
1.245\end{array}$ & $<.001$ & 190 & 1.166 & $\begin{array}{l}1.094- \\
1.242\end{array}$ & $<.001$ \\
\hline $\begin{array}{l}\text { Severity of problems } \\
\text { with peers }\end{array}$ & 244 & 1.125 & $\begin{array}{l}1.055- \\
1.199\end{array}$ & $<.001$ & 244 & 1.098 & $\begin{array}{l}1.031- \\
1.168\end{array}$ & 0.004 & 244 & 1.120 & $\begin{array}{l}1.050- \\
1.193\end{array}$ & 0.001 \\
\hline
\end{tabular}




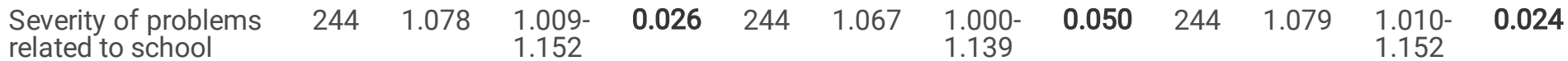
1.152

Univariable analysis: individual binary logistic regression analyses of each candidate factor performed separately; N: Number of patients; OR: Odds ratio; $\mathrm{Cl}$ : Confidence interval; $P$-value $<0.100$ is considered statistically significant 
Table 3. Multivariable analyses of factors associated with patient-clinician discordance on unmet care needs with regard to mental health problems

\begin{tabular}{|c|c|c|c|c|c|c|c|c|c|c|c|c|}
\hline & \multicolumn{4}{|c|}{ Child multivariable model } & \multicolumn{4}{|c|}{ Child and parent multivariable model } & \multicolumn{4}{|c|}{$\begin{array}{l}\text { Child, parent and family/social } \\
\text { context multivariable model }\end{array}$} \\
\hline & $\mathrm{N}$ & OR & $\begin{array}{l}95 \% \\
\mathrm{Cl}\end{array}$ & $P$ & $\mathrm{~N}$ & OR & $95 \% \mathrm{Cl}$ & $P$ & $\mathrm{~N}$ & OR & $\begin{array}{l}95 \% \\
\mathrm{Cl}\end{array}$ & $P$ \\
\hline Child level & 243 & - & - & - & 243 & - & - & - & 186 & & & \\
\hline $\begin{array}{l}\text { Severity of } \\
\text { psychiatric } \\
\text { problems }\end{array}$ & & 1.072 & $\begin{array}{l}1.011- \\
1.137\end{array}$ & 0.020 & & 0.992 & $0.938-1.048$ & 0.769 & & & & \\
\hline $\begin{array}{l}\text { Severity of } \\
\text { internalizing } \\
\text { problems }\end{array}$ & & 1.041 & $\begin{array}{l}0.905- \\
1.199\end{array}$ & 0.572 & & & & & & & & \\
\hline \multicolumn{13}{|l|}{$\begin{array}{l}\text { Dangerous } \\
\text { behavior }\end{array}$} \\
\hline $\begin{array}{l}\text { Dangerous } \\
\text { behavior } \\
\text { towards self } \\
\text { (yes/no) }\end{array}$ & & 4.187 & $\begin{array}{l}2.187- \\
8.015\end{array}$ & $<.001$ & & 3.813 & 1.918-.7.579 & $<.001$ & & 3.716 & $\begin{array}{l}1.558- \\
8.867\end{array}$ & 0.003 \\
\hline $\begin{array}{l}\text { Rule-breaking } \\
\text { behavior } \\
\text { (yes/no) }\end{array}$ & & 2.927 & $\begin{array}{l}1.517- \\
5.647\end{array}$ & 0.001 & & 2.398 & $1.151-4.995$ & 0.019 & & 3.086 & $\begin{array}{l}1.273- \\
7.481\end{array}$ & 0.013 \\
\hline Age & 243 & 1.304 & $\begin{array}{l}0.662- \\
2567\end{array}$ & 0.443 & & & & & & & & \\
\hline $4-11$ & 90 & & & & & & & & & & & \\
\hline $12-18$ & 153 & & & & & & & & & & & \\
\hline
\end{tabular}

\section{Parent level}

\begin{tabular}{|c|c|c|c|c|c|c|}
\hline $\begin{array}{l}\text { Degree of } \\
\text { parental stress }\end{array}$ & 1.311 & $1.110-1.549$ & 0.001 & 1.233 & $\begin{array}{l}1.021- \\
1.490\end{array}$ & 0.030 \\
\hline $\begin{array}{l}\text { Severity of } \\
\text { parent's } \\
\text { psychiatric } \\
\text { problems }\end{array}$ & 1.180 & $1.104-1.261$ & 0.001 & 1.137 & $\begin{array}{l}1.054- \\
1.227\end{array}$ & 0.001 \\
\hline
\end{tabular}

\section{Family/social context level}

Child growing up in a singleparent

household

\section{Degree of} discordance between parent and child on the child's mental

health

problems

Severity of problems with $3.022 \quad \begin{aligned} & 1.300 \\ & \\ & 7.025\end{aligned}$

peers

\section{Problems} related to school 
Multivariable analysis: binary regression analyses of the predictors that were significant in the univariable analysis, performed simultaneously; $n$ : number of patients; Cl: Confidence interval; P-value $<0.100$ is considered statistically significant;

Child-level: Omnibus test, Step $P=0.000$, Model $P=<0.000$, Hosmer-Lemeshow, $P=0.058$, Nagelkerke R2=0.295

Child-parent-level: Omnibus test, Step $P=0.000$, Model $P=<0.000$, Hosmer-Lemeshow, $P=0.437$, Nagelkerke R2=0.499

Child-parent-family/social-context level: Omnibus test, Step $P=0.000$, Model $P=<0.000$, Hosmer-Lemeshow, $P=0.645$, Nagelkerke R2=0.575 
Table 4. Multivariable analyses of factors associated with patient-clinician discordance on unmet care needs with regard to information regarding diagnosis and/or treatment

\begin{tabular}{|c|c|c|c|c|c|c|c|c|c|c|c|c|}
\hline & \multicolumn{4}{|c|}{ Child multivariable model } & \multicolumn{4}{|c|}{ Child and parent multivariable model } & \multicolumn{4}{|c|}{$\begin{array}{l}\text { Child, parent and family/social } \\
\text { context } \\
\text { multivariable model }\end{array}$} \\
\hline & $\mathrm{N}$ & OR & $\begin{array}{l}95 \% \\
\mathrm{Cl}\end{array}$ & $P$ & $\mathrm{~N}$ & OR & $95 \% \mathrm{Cl}$ & $P$ & $\mathrm{~N}$ & OR & $\begin{array}{l}95 \% \\
\mathrm{Cl}\end{array}$ & $P$ \\
\hline Child level & 243 & - & - & - & 243 & - & - & - & 186 & & & \\
\hline $\begin{array}{l}\text { Severity of } \\
\text { psychiatric } \\
\text { problems }\end{array}$ & & 1.061 & $\begin{array}{l}1.099- \\
1.116\end{array}$ & 0.020 & & 1.034 & $0.985-1.085$ & 0.179 & & & & \\
\hline $\begin{array}{l}\text { Severity of } \\
\text { internalizing } \\
\text { problems }\end{array}$ & & 0.992 & $\begin{array}{l}0.899- \\
1.094\end{array}$ & 0.866 & & & & & & & & \\
\hline $\begin{array}{l}\text { Severity of } \\
\text { externalizing } \\
\text { problems }\end{array}$ & & 1.121 & $\begin{array}{l}0.972- \\
1293\end{array}$ & 0.118 & & & & & & & & \\
\hline $\begin{array}{l}\text { Dangerous } \\
\text { behavior } \\
\text { towards self } \\
\text { (yes/no) }\end{array}$ & & 4.249 & $\begin{array}{l}2.282- \\
7.911\end{array}$ & $<.001$ & & 2.997 & $1.621-.5 .540$ & $<.001$ & & 3.334 & $\begin{array}{l}1.478- \\
7.517\end{array}$ & 0.004 \\
\hline $\begin{array}{l}\text { Rule-breaking } \\
\text { behavior } \\
\text { (yes/no) }\end{array}$ & & 2.276 & $\begin{array}{l}1.239- \\
4.182\end{array}$ & 0.008 & & 2.002 & $1.063-3.769$ & 0.032 & & 1.920 & $\begin{array}{l}0.858- \\
4.300\end{array}$ & 0.113 \\
\hline
\end{tabular}

\section{Parent level}

\begin{tabular}{|c|c|c|c|c|c|c|}
\hline $\begin{array}{l}\text { Degree of } \\
\text { parental stress }\end{array}$ & 1.069 & $0.929-1.229$ & 0.352 & & & \\
\hline $\begin{array}{l}\text { Severity of } \\
\text { parent's } \\
\text { psychiatric } \\
\text { problems }\end{array}$ & 1.107 & $1.047-1.170$ & $<.001$ & 1.125 & $\begin{array}{l}1.054- \\
1.200\end{array}$ & $<.001$ \\
\hline
\end{tabular}

\section{Family/social context level}

Child growing up in a single-

parent

household

\section{Degree of} discordance

between

parent and

child on the severity of the child's mental health problems

\section{Severity of} problems with $2.336 \quad 1.076-$ 0.032 peers

Problems related to school 
related to

school

Multivariable: binary regression analyses of the predictors that were significant in the univariable analysis, performed simultaneously; $\mathrm{n}$ : number of patients; $\mathrm{Cl}$ : Confidence interval; $P$-value $<0.100$ is considered statistically significant;

Child-level: Omnibus test, Step $P=0.000$, Model $P=<0.000$, Hosmer-Lemeshow, $P=0.346$, Nagelkerke $R^{2}=0.261$

Child-parent-level: Omnibus test, Step $P=0.000$, Model $P=<0.000$, Hosmer-Lemeshow, $P=0.917$, Nagelkerke $R^{2}=0.329$

Child-parent-family/social-context-level: Omnibus test, Step $P=0.000$, Model $P=<0.000$, Hosmer-Lemeshow, $P=0.571$, Nagelkerke $\mathrm{R}^{2}=0.451$ 
Table 5. Factors associated with patient-clinician discordance on unmet care needs with regard to making and keeping friends.

\begin{tabular}{|c|c|c|c|c|c|c|c|c|c|c|c|c|}
\hline & \multicolumn{4}{|c|}{ Child multivariable model } & \multicolumn{4}{|c|}{ Child and parent multivariable model } & \multicolumn{4}{|c|}{$\begin{array}{l}\text { Child, parent and family/social } \\
\text { context multivariable model }\end{array}$} \\
\hline & $\mathrm{N}$ & OR & $\begin{array}{l}95 \% \\
\mathrm{Cl}\end{array}$ & $P$ & $\mathrm{~N}$ & OR & $95 \% \mathrm{Cl}$ & $P$ & $\mathrm{~N}$ & OR & $95 \% \mathrm{Cl}$ & $P$ \\
\hline Child level & 243 & - & - & - & 243 & - & - & - & 181 & & & \\
\hline $\begin{array}{l}\text { Severity of } \\
\text { psychiatric } \\
\text { problems }\end{array}$ & & 1.114 & $\begin{array}{l}1.049- \\
1.247\end{array}$ & 0.002 & & 1.049 & 0.993-1.109 & 0.088 & & 1.079 & $\begin{array}{l}1.006- \\
1.156\end{array}$ & 0.032 \\
\hline $\begin{array}{l}\text { Severity of } \\
\text { internalizing } \\
\text { problems }\end{array}$ & & 0.963 & $\begin{array}{l}0.823- \\
1.128\end{array}$ & 0.644 & & & & & & & & \\
\hline $\begin{array}{l}\text { Severity of } \\
\text { externalizing } \\
\text { problems }\end{array}$ & & 0.996 & $\begin{array}{l}0.790- \\
1259\end{array}$ & 0.975 & & & & & & & & \\
\hline \multicolumn{13}{|l|}{$\begin{array}{l}\text { Dangerous } \\
\text { behavior }\end{array}$} \\
\hline $\begin{array}{l}\text { Dangerous } \\
\text { behavior } \\
\text { towards self } \\
\text { (yes/no) }\end{array}$ & & 4.955 & $\begin{array}{l}2.493- \\
9.849\end{array}$ & $<.001$ & & 4.458 & 2.239-.8.875 & $<.001$ & & 4.691 & $\begin{array}{l}1.918- \\
11.476\end{array}$ & 0.001 \\
\hline $\begin{array}{l}\text { Rule-breaking } \\
\text { behavior } \\
\text { (yes/no) }\end{array}$ & & 2.709 & $\begin{array}{l}1.389- \\
5.281\end{array}$ & 0.003 & & 2.286 & $1.110-4.710$ & 0.025 & & 1.807 & $\begin{array}{l}0.752- \\
4.341\end{array}$ & 0.186 \\
\hline Age & 243 & 1.642 & $\begin{array}{l}0.814- \\
3.314\end{array}$ & 0.166 & & & & & & & & \\
\hline $4-11$ & 90 & & & & & & & & & & & \\
\hline $12-18$ & 153 & & & & & & & & & & & \\
\hline
\end{tabular}

\section{Parent level}

\begin{tabular}{|c|c|c|c|c|c|c|}
\hline $\begin{array}{l}\text { Degree of } \\
\text { parental } \\
\text { stress }\end{array}$ & 1.162 & $0.991-1.363$ & 0.065 & 1.172 & $\begin{array}{l}0.970- \\
1.416\end{array}$ & 0.099 \\
\hline \multicolumn{7}{|l|}{$\begin{array}{l}\text { Psychiatric } \\
\text { problems }\end{array}$} \\
\hline $\begin{array}{l}\text { Severity of } \\
\text { parent's } \\
\text { psychiatric } \\
\text { problems }\end{array}$ & 1.166 & $1.093-1.244$ & $<.001$ & 1.114 & $\begin{array}{l}1.032- \\
1.202\end{array}$ & 0.006 \\
\hline
\end{tabular}

\section{Family/social- context level}

Child growing up in a singleparent household

\section{Degree of} discordance between parent and child on the severity of the child's mental health problems 
elated to

school

Multivariable: binary regression analyses of the predictors that were significant in the univariable analysis, performed simultaneously; $\mathrm{n}$ : number of patients; $\mathrm{Cl}$ : Confidence interval; $P$-value $<0.100$ is considered statistically significant;

Child-level: Omnibus test, Step $P=0.000$, Model $P=<0.000$, Hosmer-Lemeshow, $P=0.657$, Nagelkerke $\mathrm{R}^{2}=0.368$

Child-parent-level: Omnibus test, Step $P=0.000$, Model $P=<0.000$, Hosmer-Lemeshow, $P=0.969$, Nagelkerke $R^{2}=0.496$

Child-parent-family/social-context-level: Omnibus test, Step $P=0.000$, Model $P=<0.000$, Hosmer-Lemeshow, $P=0.403$, Nagelkerke $\mathrm{R}^{2}=0.542$

\section{Figures}

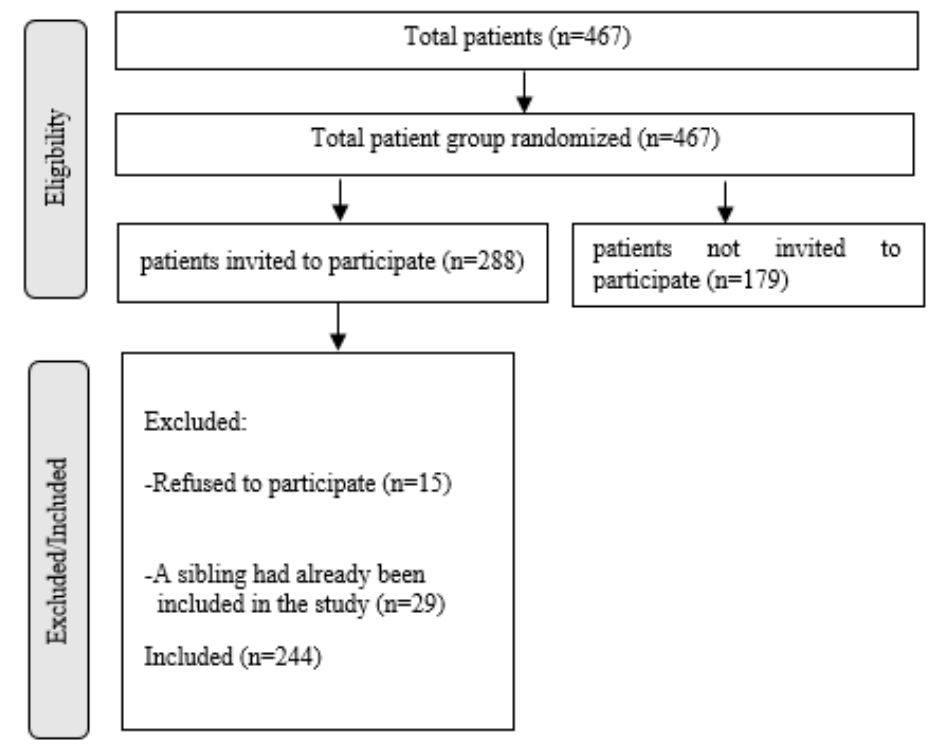

\section{Figure 1}

Participant flow diagram. 